\title{
ORIXÁ, NATUREZA E HOMEM: UM SÓ ECOSSISTEMA - USOS DE PLANTAS NOS TERREIROS DE CANDOMBLÉ E UMBANDA NO SERTÃO DO BRASIL
}

\section{ARTIGO ORIGINAL}

SANTOS, Lílian Pinto da Silva ${ }^{1}$, SANTOS, Juracy Marques dos ${ }^{2}$

SANTOS, Lílian Pinto da Silva. SANTOS, Juracy Marques dos. Orixá, natureza e homem: um só ecossistema - usos de plantas nos terreiros de candomblé e Umbanda no sertão do Brasil. Revista Científica Multidisciplinar Núcleo do Conhecimento. Ano 06, Ed. 06, Vol. 01, pp. 21-37. Junho de 2021. ISSN: 2448-0959, Link de acesso: https://www.nucleodoconhecimento.com.br/cienciassociais/natureza-e-homem, DOI: 10.32749/nucleodoconhecimento.com.br/cienciassociais/natureza-e-homem

\section{RESUMO}

No contexto dos rituais afro-brasileiros e indígenas é imprescindível a utilização de vegetais e animais no que se refere ao valor simbólico e espiritual, através de atividades místicas em forma de oferendas, individual ou coletivamente. A questão motivadora desta pesquisa foi: quais os sentidos do uso das plantas nos rituais sagrados do Candomblé e da Umbanda no Sertão? Para essas culturas humanas milenares, que trazem consigo um vasto conhecimento sobre as mais diversas formas de proficuidade desses elementos, é também pelas irradiações e vibrações energéticas que se dá o processo terapêutico, para além da cura do corpo físico. Este estudo foi desenvolvido através da análise dos discursos presentes nas Cartografias Sociais dos Terreiros de Paulo Afonso, Jaguarari, Petrolina e Juazeiro e Senhor do

\footnotetext{
${ }^{1}$ Mestranda em Ecologia Humana, pós-graduada em Neuroaprendizagem, Graduada em Pedagogia.

${ }^{2}$ Orientador. Doutorado em andamento em Ecologia Humana.
} 
Bonfim $(2009 ; 2010 ; 2015 ; 2018)$, buscando compreender a forma de organização dos terreiros de Candomblé e Umbanda e suas relações com os ecossistemas no sertão brasileiro. O caminho que percorremos neste trabalho deu-se a partir da construção dos sentidos simbólicos, das vivências e saberes dos povos do Candomblé e da Umbanda sertanejos destacando as práticas destas religiões como narrativas dos sujeitos da pesquisa contidas neste vasto material resultante de mais de dez anos de pesquisas de campo.

Palavras-chave: Terreiros, plantas, religiosidade

\section{INTRODUÇÃO}

A relação entre homem e natureza, de forma associativa, excedeu-se em domínio alicerçado no atributo da razão, que outorgou ao homem o direito e encargo da domesticação de plantas e animais, conforme Moura; Marques (2008). A utilização de elementos biológicos dos ecossistemas alheios ao próprio corpo para a manutenção do metabolismo é a fundamentação vital de seres biologicamente classificados como heterotróficos, os que não produzem organicamente seus próprios alimentos. Para Huffman (1997); Hutchings et al. (2003) é de conhecimento dos primatas, aves, rinocerontes, elefantes e roedores a utilização de minerais e vegetais como produtos medicinais para antídoto contra toxinas, controle de hormônios, controle de parasitas, ainda como antibióticos e estimulantes.

Para Huffman (1997); e Hutchings et al. (2003) o uso de vegetais e minerais com potencial medicinal é conhecido em animais como primatas, aves, lobos, elefantes, rinocerontes e roedores, visando à ação antimicrobiana, estimulante, laxante, antiparasitária, antibiótica, controladora hormonal e como antídoto contra toxinas.

A medicina popular, também chamada de tradicional, beneficia cerca de $80 \%$ da população do mundo, segundo estimativa da Organização Mundial da Saúde. Assim sendo, justifica o estímulo a pesquisas etnográficas, farmacológicas, médicas e ecológicas que são de muita relevância para a fundamentação dos saberes populares 
no meio científico para fins de aquisição de novos medicamentos e terapias, como nos indicam Moura; Marques (2008) e Alves (2010)

Sendo o país mais abundante em biodiversidade terrestre do planeta, o Brasil abriga cerca de $20 \%$ das espécies animais, vegetais e microrganismos do mundo (NOGUEIRA et al., 2010),destaca-se ainda por ser um dos países de maior diversidade genética vegetal, contando com mais de 55.000 espécies catalogadas, como afirma Nodari; Guerra (1999).

Marcada por uma grande utilização etnofarmacológica de diversas plantas por comunidades locais, o Nordeste caracteriza-se ainda pela transmissão desse saber tradicional e popular de geração a geração, sendo possível observar um vasto conhecimento de métodos terapêuticos para a cura ou alívio de algumas doenças. (BAPTISTEL et al., 2014).

No contexto do sertão, marcado por uma vegetação contida em uma área de caatinga, determinado por um clima predominantemente semiárido no qual há baixa oferta de água e é extremamente variável - ao contrário do que se pensava outrora - há uma grande variação de condições ambientais, essenciais tanto para o surgimento quanto para a sobrevivência de várias espécies que se adaptam bem ao clima dessa região, como destaca Andrade (2013).

Ocupando atualmente $11 \%$ do território nacional e com a extensão de aproximadamente 845 mil quilômetros quadrados, a caatinga, ainda segundo Andrade (2013), divide-se em oito ecorregiões bem distintas no tocante às paisagens, vegetações, tipos de solo. Em algumas destas as chuvas não chegam a atingir mil milímetros $(\mathrm{mm})$ no decorrer do ano. Apesar das circunstâncias supracitadas, a caatinga possui grande variedade de plantas, muitas delas, endêmicas. Estima-se que, das 6 mil espécies, distribuídas em 1.333 gêneros, 18 são próprios da região e das 87 espécies de cactos, $83 \%$ são exclusivas desse ecossistema.

De uma riqueza inestimável, a caatinga também é um bioma rico em espécies animais, havendo estudos que apontam a existência de aproximadamente 327 espécies 
endêmicas. Há registros de 178 espécies de mamíferos, 591 espécies de aves, 177 espécies de répteis, 79 espécies de anfíbios, 241 espécies de peixes e 221 espécies de abelhas, segundo o Ministério do Meio Ambiente, e estima-se ainda que são típicos da caatinga 13 espécies de mamíferos, 23 de lagartos, 20 de peixes e 15 de aves.

Para além das belezas e riquezas dessa mata branca, aqui fazemos referência à língua Tupi na qual a palavra caatinga é atribuída à vegetação deste bioma. Esta pesquisa nas casas santas dos Terreiros de Candomblé e Umbanda no Sertão traz uma vasta relação dos povos tradicionais e os meios com os quais se relacionam com os ecossistemas através do seu sagrado.

\section{A PESQUISA}

Os processos de adaptação e resistência vivenciados por parte dos homens e mulheres escravizados no passado, quer sejam indígenas ou africanos, nos legaram a manutenção de valores de uma cosmovisão diferenciada, que fez sobreviver línguas, tradições culturais e outras formas de se relacionar com o sagrado por meio da natureza. Esses valores foram salvaguardados no universo dos terreiros, territórios de matriz africana e indígena no Brasil. Conforme Hampaté Bâ (1982):

$\mathrm{Na}$ cultura africana, tudo é "História". A grande história da vida compreende a história da terra e das águas (geografia); a história dos vegetais (botânica e farmacopeia); a história dos "filhos do seio da Terra" (mineralogia e metais); a história dos astros (astronomia, astrologia), a história das águas, e assim por diante [...] Por exemplo, o mesmo velho conhecerá não apenas a ciência das plantas (as propriedades boas e más de cada planta), mas também "as ciências da terra" (as propriedades agrícolas ou medicinais dos diferentes tipos de solo), a ciência das águas, astronomia, cosmogonia, psicologia... Trata-se de uma ciência da vida, cujos conhecimentos sempre podem favorecer uma utilização prática. E quando falamos de ciências "iniciatórias" ou ocultas, termos que podem confundir o leitor racionalista, trata-se sempre, para a Africa tradicional, de uma ciência eminentemente prática que consiste em saber como entrar em relação apropriada com as forças que sustentam o mundo visível, e que podem ser colocadas a serviço da vida (HAMPATÉ BÂ 1982, p. 195)

Quanto às mitologias e as cosmologias indígenas, elas tratam de temas com que se preocupam todos os homens, com menor ou maior grau de elaboração, expressão ou 
consciência. Camargo (1994) demonstra que a cosmovisão indígena possui, enquanto princípio, a tomada da vida em complementaridade, indicando que nas comunidades, os seres se complementam. Para esse autor, enquanto sociedades igualitárias e sem divisão de classes sociais, nem separação entre possuidores dos meios de produção, as comunidades indígenas se organizam a partir da posse coletiva de terras e dos recursos que nelas existem logo, a socialização dos saberes básicos é indispensável à sobrevivência tanto física quanto cultural e social dos seus membros. Dessa forma, a incompletude do ser se transforma em convivência harmônica e questão fundamental de sobrevivência.

Isto posto, é necessário que se faça a reflexão acerca dos processos de resistência desses povos que apesar e por causa dos crimes de lesa-humanidade vividos ao longo dos séculos estabeleceram através do respeito e do diálogo a mais legítima troca de saberes ancestrais. Saberes esses que trazem no seu cerne a reverência às forças da natureza como reflexos das emanações dos Orixás, Encantados e Inkises na Terra, e que, portanto, poluir o ar, desperdiçar a água, destruir as árvores, desrespeitar a humanidade são práticas contrárias à aprendizagem dos espaços sagrados dos Terreiros.

Conforme Oxóssi (2020), desde a chegada dos primeiros negros no Brasil, a medicina tradicional e a medicina natural já se confundiam nas comunidades e antes mesmo disso, o conhecimento das propriedades mágicas e terapêuticas dos vegetais já era notado através do contado dos indígenas que aqui habitavam e já tinham na natureza seu meio de existência e sobrevivência.

Para Barros; Napoleão (2011) foi através da organização dos primeiros candomblés que essa prática ganhou notoriedade e em especial pelo seu caráter espiritual. Para esse autor, não foi apenas a criação de locais de culto aos Orixás mas, espaços de memória das origens e tradições onde se celebra a ida de uma maneira muito particular.

Assim sendo, os negros escravizados, para fins de adaptação às suas novas condições de vida, ressignificaram uma série de costumes e ritos agregando à sua 
cultura original diversos aspectos que aqui encontraram através do contato com os indígenas e com os europeus. Oxóssi (2020) acrescenta que foram descobertos novos ingredientes e maneiras de trabalhar com os elementos naturais que, apesar do clima muito semelhante, diferiam em diversos aspectos de produção e de oferta.

Procedeu-se à coleta do material citado pelos Sacerdotes e Sacerdotisas que compõem as Cartografias Sociais dos Terreiros de Paulo Afonso, Jaguarari, Petrolina e Juazeiro e Senhor do Bonfim (2009; 2010; 2015; 2018). As espécies de plantas medicinais levantadas foram identificadas e incluídos seus respectivos nomes de acordo com o sistema APG (THE ANGIOSPERM PHYLOGENY GROUP, 2003) e no Registro Nacional de Cultivares. Com base nas informações obtidas, foi elaborada uma listagem de espécies organizada por nomes populares seguidos pelo nome científico, origem e número de citações.

\section{USOS DAS PLANTAS PELOS TERREIROS CARTOGRAFADOS}

Totalizando 51 entrevistados em 27 Terreiros que se identificam como Candomblé, outros 21 Terreiros de Umbanda, 02 que se autodenominam Umbanda com Candomblé e 01 intitulado Mesa Branca, foram identificadas 27 espécies vegetais originárias dos mais diversos continentes. Dessas, 07 são originárias do Brasil Gameleira (Ficusdoliaria), Jatobá (Hymenaeacourbaril L), Jurema (Mimosa hostilisBenth) / (Mimosa tenuiflora Willd), Licuri (Sygrus Cronata), Mulungú (Erythrina verna Vell), Pau Ferro (Caesalpinialeiostachya), Pitangueira (Eugenia uniflora) Quadro 1. Lista de espécies de plantas medicinais e litúrgicas citadas nas Cartografias Sociais dos Terreiros de Paulo Afonso, Jaguarari, Petrolina e Juazeiro e Senhor do Bonfim (2009; 2010; 2015; 2018).

Quadro 1. Lista de espécies de plantas medicinais e litúrgicas citadas nas Cartografias Sociais dos Terreiros de Paulo Afonso, Jaguarari, Petrolina e Juazeiro e Senhor do Bonfim (2009; 2010; 2015; 2018). 


\begin{tabular}{|c|c|c|c|}
\hline $\begin{array}{l}\text { Espécies } \\
\text { vegetais } \\
\text { (nomes } \\
\text { populares) }\end{array}$ & Nome científico & Origem & $\begin{array}{l}\text { Quantidade de } \\
\text { citações }\end{array}$ \\
\hline Abacateiro & Persea americana & $\begin{array}{l}\text { Continente } \\
\text { Americano }\end{array}$ & 01 \\
\hline Akoko & Newbouldialaevis & $\begin{array}{l}\text { Continente } \\
\text { Africano }\end{array}$ & 01 \\
\hline Arruda & Rutagraveolens L & Europa Meridional & 01 \\
\hline Canela & Cinnamomumzeylanicum & Siri Lanka & 01 \\
\hline Coqueiro & Cocos nucifera & $\begin{array}{l}\text { Continente } \\
\text { Americano }\end{array}$ & 01 \\
\hline Erva-doce & Pimpinellaanisum L. & Ásia & 01 \\
\hline Folha de colônia & Alpina speciosa & Ásia & 01 \\
\hline Gameleira & Ficusdoliaria & Brasil & 02 \\
\hline Guiné & Panicummaximumjacq & África & 01 \\
\hline Jaqueira & Artocarpusheterophyllus & Índia & 02 \\
\hline Jatobá & Hymenaeacourbaril L & Brasil & 02 \\
\hline Jurema & $\begin{array}{l}\text { Mimosa hostilisBenth } \\
\text { Mimosa } \\
\text { tenuiflora Willd. }\end{array}$ & Brasil & 02 \\
\hline Laranjeira & Citrussinensis L. & Ásia & 02 \\
\hline Levante & Menthavirids $L$. & Mediterrâneo & 01 \\
\hline Licuri & SygrusCronata & Brasil & 01 \\
\hline Mangueira & Mangifera indica & Índia & 02 \\
\hline Milho branco & Zeamays & México & 01 \\
\hline Mulungú & Erythrina verna Vell & Brasil & 01 \\
\hline Pau-ferro & Caesalpinialeiostachya & Brasil & 01 \\
\hline Peregun & Dracaenafragance & África & 01 \\
\hline Pitangueira & Eugenia uniflora & Brasil & 01 \\
\hline $\begin{array}{l}\text { Total de espécies } \\
\text { citadas }\end{array}$ & & & 27 \\
\hline
\end{tabular}

RC: 87218

Disponível em: https://www.nucleodoconhecimento.com.br/ciencias-sociais/natureza-e-homem 
Fonte:

Registro

nacional

de

cultivares

RNC,

disponível

em: http://sistemas.agricultura.gov.br/snpc/cultivarweb/cultivares_registradas.php

Optamos por trazer inicialmente os discursos dos dirigentes dos Terreiros, sacerdotes e sacerdotisas, em que são citadas as ervas e posteriormente teceremos comentários mais específicos acerca dos seus usos

Sobre os usos das ervas nos rituais sagrados, o Sacerdote do Terreiro de Umbanda Centro de Ogum Beira-mar, nação Ketu, situado no Município de Paulo Afonso, Bahia, infere:

As ervas medicinais são usadas para as curas, para os banhos, a arruda para preparar os banhos, as folhas das laranjas, o sal de pedra, folha de manga para espantar espíritos maus, a folha de guiné que é uma planta que muitas vezes o povo diz: o que é guiné? É o tipi, é a corrente do tipi. A folha do levante que muitas vezes as pessoas não conhecem que são folhas de colônia. Folhas de peregum que é uma planta que ela é nascida nas matas e serve para fazer o lavamento da cabeça para a cura e é a concentração do batismo dos orixás.

Usa a jurema tanto para o banho como a usa a casca pra fazer o vinho para os filhos tomar aquele vinho como uma cura. É um vinho feito com a casca da jurema, não se bota álcool por que ele é um vinho purificado, igualmente os padres fazem os seus vinhos purificados para acompanhar o corpo de Cristo que é a hóstia.

Aqui nós temos a hóstia que é feita com pão, com pedaços de pão, fatias de pão. Ai ali nós fazemos aquele ritual que é para os filhos de santo, os filhos de santo vão passar sete dias, eles vão comer esse pão, vão comer peixe, frutas e arroz branco. Eles não vão comer feijão, eles não vão comer o macarrão, não vão comer carne vermelha, porque não pode.

Eles vão comer apenas carne de frango, peixe, pão, frutas e arroz branco. Os sete dias que eles estão de quarto. O banho da jurema é pra tirar os maus olhados, para afastar os maus olhados, qualquer tipo de quebrante tira com as folhas da jurema. Faz o banho e depois toma, ai você está preparado, pois está limpo, ai faz o fechamento de corpo em você como se fosse um batismo pelas correntes das folhas dos orixás.

Por que senão, não fica completo, você vai entrar sete dias de quarto para dar um bori, se você não foi lavado, se você não foi batizada, não adiantou nada o seu bori, o seu bori não saiu completo. Então o batismo é com o bori. (MARQUES 2009;101/102/103). 
- A arruda, Rutagraveolens L, planta originária da Europa Meridional tem grande importância para os povos tradicionais de Terreiro. Oxóssi (2020, p. 36) atribui a arruda propriedades energéticas de proteção espiritual e cortar energias negativas além de servir de amuleto para olho grande expressão utilizada para designar inveja- e maus fluídos, intensifica a força de vontade auxiliando o indivíduo à realização dos seus desejos.

- Folhas de laranja, Citrussinensis L., têm propriedade relaxante aliviando insônia e nervosismo. Energeticamente, para Oxóssi (2020, p. 94) ajuda no desenvolvimento da mediunidade e clarividência, atrai amor e favorece a conquista de bens materiais. Alivia ainda sentimentos de solidão e abandono. Por ser uma folha pertencente ao Orixá Oxalá e pertencente ao elemento ar, traz harmonia e calma.

- As Folhas de manga, Mangifera indica, segundo Oxóssi (2020, p. 103), pertencem ao Orixá Omolu e ao elemento terra, é utilizada em rituais de descarrego e limpeza espiritual.

- Guiné, Panicum maximum jacq, pertencente aos Orixás Ossain e Oxóssi, indica Oxóssi (2020, p. 87) que assim como as folhas de manga também estão relacionadas ao elemento terra e seu uso é feito em rituais de descarrego e limpeza espiritual.

- Colônia/levante ou alevante, Menthavirids L., possui a propriedade fitoterápica de auxiliar no combate a insônia e nervosismo. Como remédio caseiro põe fim aos males do estômago se usado como chá (pendão ou cacho floral). Energeticamente, Oxóssi (2020, p. 66) diz que esta planta abre caminhos, equilibra as emoções, alivia traumas e choques emocionais, traz força e coragem para enfrentar os desafios além de trazer harmonia e paz aos pensamentos. Tem como Orixás regentes Ogum e Oxalá e pertence ao elemento fogo.

- Peregum, Dracaenafragance, pertence ao elemento terra e tem como Orixás regentes Logunedé e Oxóssi. Abre os caminhos, atrai boas energias, fortalece a mediunidade e a espiritualidade. Oxóssi (2020, p. 122) indica que esta planta traz força e coragem para enfrentar os desafios.

Sobre os usos das ervas, a Senhora Josefa dos Santos Dias, dirigente do Centro Espiritual Umbanda, situado na cidade de Jaguarari, Bahia afirma:

Eu defumo com incenso, com azeite doce, com ervas, folhas de pitanga, cascas de laranja. O significado é porque ele traz a cura que é a paz, faz o retiro. Então os habitantes que vêm pra se acumular o incenso faz o retiro, ele limpa (MARQUES, 2010, p. 209). 
- Pitangueira, Eugenia uniflora, tem como regente a Orixá lansã, elemento fogo. Suas folhas são utilizadas para abris caminhos, conforme Oxóssi (2020, p. 126), suas folhas atraem boas energias e amor, fortalecem a mediunidade e também as amizades. Chamada ìtà em Yorùbà, segundo Barros pertence ao orixá Ossanyn e é classificada no compartimento terra. Varella e Silva (1973) fazem uma associação dessa planta ao orixá Oxóssi para defumação e junto com canela, cravo, café e açúcar para melhorar as finanças.

Nas Cartografias Sociais dos Terreiros de Petrolina, Pernambuco, encontramos na fala do Babalorixá Valter d'Oxum, conhecido como Pai Valter, sacerdote do Terreiro Nossa Senhora das Candeias, pertencente a Nação Ketu:

Para aqui trouxe vários aprendizados do Candomblé. Eu trouxe muita alegria, trouxe muito samba, trouxe muita cantiga, tá entendendo? As pessoas é que não souberam aproveitar, sabe? O akokô, essa planta de poder que tem em todo Candomblé aqui, quem trouxe fui eu. $\mathrm{O}$ primeiro pé de akokô. Inicialmente coloquei uma muda em casa, depois sai distribuindo. (2015, p. 115)

(...) Olhe! Todas as plantas são fundamentais no Candomblé, particularmente as fruteiras. Mas o akokô, eles identificaram como sendo, não uma planta frutífera, mas como uma planta de axé que existia na África. É como a gameleira, tá entendendo? Como o mulungu. Por exemplo, o pé-de-jaca é uma planta de fundamento. Tem de manga, tem de abacate, mas aí são plantas frutíferas; agora, as plantas que não davam frutos o akokô está incluído como numa das plantas de axé, de crescer. Apesar de ser um segredo em si, ela tem um santo, que não vou dizer o nome, ela tem uma identidade com um santo, ela tem muito fundamento, tanto pra banho como para outros fins. Eles chamam bejereçú, uma daquelas coisas secreta no Candomblé (MARQUES; NOVAES, 2015, p. 121)

- A planta akoko, Newbouldialaevis, originária do continente africano, mais especificamente da Nigéria, é uma das mais importantes e sagradas dentro do culto do candomblé brasileiro, estando bastante difundida e aclimatada no nosso país. Para Barros; Napoleão (2011) é considerada uma das mais importantes e sagradas do culto aos Deuses Africanos. As folhas de Akoko são tão importantes, que são utilizadas para consagrar os títulos honoríficos e religiosos que os seguidores do Candomblé recebem. Suas folhas ainda são utilizadas em diversos rituais, bem como o seu tronco. Seus galhos possuem uma forte ligação com os ancestrais. Há ainda, Divindades que 
moram aos pés dessa árvore. Na África, por exemplo, existem assentamentos de Ogum, o Deus Guerreiro, aos pés dessa árvore.

- A Gameleira, Ficusdoliaria, uma planta originária do Brasil, também conhecida como Iroko, para Oxóssi (2020, p. 83), é uma planta que possui os Orixás Iroko e Oxalá como regentes. Seu elemento é o ar e é considerada a morado dos ancestrais masculinos e femininos. Considerada uma das árvores da criação do mundo, sua força de fixação espiritual é tão grande que deve ser utilizada com muita cautela.

- Mulungú, Erythrina verna Vell, planta que tem propriedades medicinais calmante é muito usada no tratamento de quadros de insônia, assim como alterações do sistema nervoso, especialmente ansiedade, agitação e convulsões. Para os povos de santo o Mulungu é utilizado para banhos ou defumação e existem relatos no candomblé, do uso de lascas do tronco ou da raiz de mulungu ao longo do período de reclusão exigido aos iniciantes, a fim de deixá-los mais tranquilos e relaxados. Os povos bantos já conheciam e utilizavam muitas árvores do gênero Erythrina, como E. abyssinica (DC.) Lam., E. caffra Thumb., E. tomentosa (A. Rich.) R. Br., E. senegalensis Chevalier. Eram conhecidas por mulungo, murungu ou mungu. Segundo Schleier; Quirino; Rahmer (2016, p. 165), existem mais de cem espécies brasileiras conhecidas como mulungu. Ainda para este autor, no nosso país os pajés de diversas etnias indígenas, em seus rituais, utilizam espécies de Erythrina como base de bebidas alucinógenas além da preparação do curare, que se trata de uma porção paralisante da musculatura, empregada para ensopar dardos e flechas para fins de pesca e caça.

- A Jaqueira, Artocarpusheterophyllus, considerada, por excelência, a morada das grandes mães ancestrais tem em seus frutos o poder de transformar o homem bruto em nobre, valioso e iluminado. Oxóssi (2020, p. 91) infere que a jaqueira pertence ao Orixá Oxóssi e tem como elemento da natureza, a terra.

- O Abacateiro, Persea Americana, originário do continente americano, sua folha é usada para banho e defumações, como função limpadora, expansora. Por ser uma erva pertencente a Oxóssi traz direção e energização.[3]

A Yalorixá Maria Filha de Souza, conhecida como Mãe Laurice, responsável pelo Centro Espírita de Umbanda Oxum lafi, Petrolina- Pernambuco, acrescenta:

Jurema é minha madrinha, Jesus é meu protetor. Jurema é um pau sagrado, onde Jesus descansou. Você que é um bom mestre, me ensine a trabalhá, com a força da Jurema e o galho do ajucá. 
(...) Na Jurema a gente prepara a casca de jurema, a casca de jatobá, e várias cascas que servem de remédio, também. A gente cozinha ou bota de molho, e prepara depois dela cozinhada. A gente bota canela, erva-doce e mais algumas para tirar o travo. Açúcar, mel, vinho, pra preparar a jurema.

(...) Agora eu lembrei de um assunto que eu não falei. Quando a gente começa a tomar jurema, o cabra sofre. Porque vem aqueles guias que vai tá com aquelas correntes, chamando... Mas, a gente sofre, viu?! Para desenvolver aquela corrente. Quando aquela corrente vem, que você já tá desenvolvido nela, já vem outro [guia]. E assim por diante: vem um, vem outro e você passando por aquilo tudo. É sofrimento, viu? Eu caia, bolava pelo chão. Teve uma vez que eu caí, desminti o pé, meu Deus do céu. Pensei: - Nunca mais que eu vou ali. Aí o guia me mandou um recado, que eu só ia ficar boa se fosse lá. Eu fui, e ele me rezou, e eu fiquei boa.

Fiz muito trabalho na mata porque eu não tinha lugar para fazer, e tinha que trabalhar na mata, mesmo. Era com os espíritos da jurema, tinha que trabalhar mais. Fazia limpeza tudim lá e lá mesmo deixava. E hoje a gente faz uma limpeza aqui, faz um sacudimento, faz lá fora, ou faz aqui dentro. Mas, tem que preparar o salão depois, tem que descarregar, tem que desfumar, tem que lavar tudo. E lá na mata, lá mesmo faz a limpeza e lá mesmo deixa aquilo tudo, e já vem limpo de lá (MARQUES; NOVAES, 2015, p.130, 139; 140/141).

Compreendemos aqui tratar-se de duas situações diferentes. Uma é o uso da planta e outra é a prática da Jurema, que para alguns também se identificam como umbandistas, espíritas ou católicos. Conforme Assunção (2010, p. 112), essa pluralidade nos permite inferir que a Umbanda é um universo que permeia diferentes práticas religiosas. A Jurema, para este autor, refere-se às entidades encantadas dos mestres e caboclos que vivem nas matas. Os seguidores a consideram uma corrente boa e quente. Boa sendo compreendida como forte, tem a sua ação imediata na resolução de problemas além de favorecer o desenvolvimento do médium.

Acerca da planta jurema, Mimosa hostilis Benth/Mimosa tenuiflora Willd, Oxóssi (2020, p. 92/93) nos informa que existem dois tipos, a jurema branca que pertence ao elemento terra e tem como orixá regente Oxóssi e a jurema preta que pertence ao elemento fogo e tem como orixá regente Exu. Ambas as ervas servem para abrir caminhos, atrair boas energias, fortalecer a mediunidade e a espiritualidade, trazer força e coragem. A jurema-preta é utilizada também em banhos fortes de descarrego. 
- O Jatobá, Hymenaeacourbaril $L$, possui propriedades medicinais expectorante, adstringente, estimulador de apetite, vermífugo, descongestionante, diurética, estomáquica, combate problemas renais e urinários, infecções intestinais e é cicatrizante. Segundo Mãe Laurice (MARQUES; NOVAES, 2015, p. 139) juntamente com a jurema e as cascas de outras ervas o jatobá pode ser utilizado na preparação de remédios.

Na Cartografia Social dos Terreiros de Senhor do Bonfim, a Yalorixá Mãe Davina Rodrigues da Silva, zeladora do Terreiro de Oxóssi, situado no Bairro São Jorge, nos diz:

Nessa época, minha mãe, Maria do Cézar, doou parte do seu terreno da fazenda para a construção da Capela de São Jorge, santo com o qual ela tinha devoção, por causa de Oxóssi. Depois que ela deu a Igreja fez a capela mas colocou o nome de Cristo Rei. Dói muito não vê as árvores que tinha.

Mas, primeiro, Deus abençoe todos nós, Oxóssi e os Orixás.

Deixa eu mostrar aqui: ali é dois pé de licuri, de gameleira e essa aí é o Jatobá. Jatobá é que é a moça. Plantou aqui que é a força da casa dela. Ela nasceu de dois. Tudo aqui, até os pé de jaca, tudo é de dois. Parece uma coisa que eu não sei como é, sabe? (MARQUES; SILVA, MARQUES, 2018, p. 16/17)

- Licuri, Sygrus Cronata, planta de origem brasileira, palmeira nativa do bioma caatinga. Espécie pode ser encontrada no norte de Minas Gerais, na porção oriental e central da Bahia até o sul de Pernambuco e nos estados de Sergipe e Alagoas. As suas folhas são utilizadas no artesanato, a amêndoa produz um óleo muito similar ao óleo de coco, utilizado na culinária e na fabricação de sabão. Sendo comestível a amêndoa também é utilizada na fabricação de cocadas, doces e licores além de outros pratos variados na cozinha baiana. Os resíduos ainda são aproveitados na alimentação animal. Para além disso, o licuri é uma árvore sagrada onde suas palhas são utilizadas para rezas e benzimentos, adornos, cobertura na entrada dos assentamentos chamados mariôs, cuja função é espantar as energias negativas e espíritos perturbadores.

Ainda sobre as árvores sagradas, o Babalorixá Antônio Alves Sobrinho, ou como prefere ser chamado, Pai Antônio D'Ogundelé, dirigente do Terreiro de Umbanda Pai 
Oxalá, também conhecido como Terreiro Tupoiaoo, Situado no bairro da Olaria, Senhor do Bonfim, Bahia infere:

Existem árvores sagradas e que pertencem aos Orixás. Toda árvore ou planta que se tem no Terreiro é sagrada. Aqui eu tenho um pé de Pau Ferro que é consagrado a Oxóssi. A Jurema é uma Cabocla dentro dos Terreiros e é uma das árvores mais sagradas dentro da Umbanda. Aqui no meu terreiro ela (a árvore Jurema) é consagrada a Exú, o Exú Orixá, o ExúBará. Porque existe o Exú Orixá e o que não é Orixá, que é um guia espiritual. Tranca Rua é o guia espiritual da casa, já o Exú Orixá da casa é Bará. (MARQUES; SILVA; MARQUES, 2018, p. 156/157).

- Pau-ferro, Caesalpinialeiostachya, árvore nativa da mata atlântica, no Brasil que possui copa arredondada e ampla, tronco claro, marmorizado e que possui folas compostas bipinadas, com folíolos de cor verde-escuro. O pau-ferro possui uma madeira dura, resistente e de excelente qualidade para a fabricação de violões e violinos, pode ser utilizado também na construção civil. Sua casca é muito usada na medicina popular, tendo propriedades anti-inflamatórias e analgésicas, anticancerígenas e anti úlceras. É utilizado para banhos e defumações. O folclorista Alceu Maynard Araújo (1964, p. 47) afirma que com a jurema se prepara o jurubari, a bebida dos encantados, dos caboclos, além de outras plantas, como umburana de cheiro (Torresia acreana) e juçá-outro nome popular para o pau-ferro(Caesalpinaferrea) em infusões com cachaça.

Para Pires et al. (2009), as plantas, no universo das religiões de matriz afro indígenas, apresentam um valor simbólico irrefutável por serem utilizadas para propósitos ritualísticos e de rotina pelas comunidades dos terreiros. $\mathrm{O}$ uso de plantas sagradas atende aos aspectos litúrgicos das casas-de-santo e possui ainda um caráter farmacobotânico, empírico e individual (BARROS, 1983; VERGER, 1995; CAMARGO, 1988).

Somam-se aos saberes milenares desses povos, um dos mais ricos frutos das culturas indígenas e negras, a necessidade da preservação dos ecossistemas por razões intrínsecas aos seus modos de vida e ao respeito às suas ancestralidades.

Evidencia-se na fala do Babalorixá Charliton Fernandes, cujo orukó[4] é Odé Irilé Taladeram Kariodé, dirigente de um Terreiro Candomblé de nações Keto e Angola, 
situada no município de Paulo Afonso- Bahia, todo um cuidado na preservação dos ecossistemas:

O Candomblé, para mim, ele é uma ciência soberba, milenar, uma fonte de conhecimento, é um auxílio, até para quem não tem conhecimento. Quem busca conhecimento, procure conhecer candomblé, assim como os gregos. Acho que o Candomblé é uma cultura excepcional, religião excepcional. Orixá é energia, orixá é natureza, acima de tudo.

Aqui, na minha casa, eu não deixo vela acesa no mato, eu não quebro garrafa em encruzilhada, porque eu respeito. Se meu orixá é natureza, porque é que eu vou fazer mal à natureza? Então, estarei fazendo mal a meu orixá. Eu me certifico que a vela foi apagada, que queimou até o fim, para que não venha causar queimadas. Candomblé para mim é respeito, é dignidade, é alegria. Candomblé para mim é tudo! (MARQUES, 2009, p. 47/48).

Diferente do pensamento hegemônico ocidental, a tradição religiosa afro-brasileira agrega importantes valores com relação a preservação das matas posto que, conforme Verger (1995):

No candomblé, a coisa mais importante é a questão das folhas, das plantas que se utilizam no momento em que se faz a iniciação. A natureza está sempre presente dentro da cerimônia. Antes de se fazer a cerimônia, a gente toma banho de certas plantas, para ter esse axé, essa força que está dentro das plantas.

Há ainda uma questão muito importante a ser destacada por nós. No cotidiano dos Terreiros há todo um cuidado na obtenção e utilização dessas ervas. Ulhôa (2011) nos informa que sendo um dos princípios fundamentais e mais importantes do candomblé a colheita de plantas da natureza, essa atividade não pode ser feita sem cuidados muito específicos, tais como preces e cantigas, as quais têm por finalidade pedir permissão e explicar à divindade os motivos da retirada necessária.

Esses espaços religiosos vivenciam as cosmologias através dos ritos e mitos onde a presença das folhas é de fundamental importância. É nessa relação de reverência e permissão que são passados os conhecimentos milenares trazidos pelos africanos da diáspora, somados aos saberes culturais indígenas e que colaboram para a constituição do Sertão do nosso país em um enorme potencial para o culto aos Orixás. 


\section{CONSIDERAÇÕES FINAIS}

A ideia inicial de fazermos um levantamento das plantas utilizadas pelos povos de terreiro do Sertão do Brasil, a partir da análise dos discursos nas Cartografias Sociais dos Terreiros de Paulo Afonso, Jaguarari, Petrolina e Juazeiro e Senhor do Bonfim (2009; 2010; 2015; 2018), buscando compreender os usos das plantas pelos povos de santo, o sistema terapêutico e outras conexões, nos levaram a caminhos que perpassaram pela atuação dessas ervas na manutenção do equilíbrio da saúde física e espiritual dessas comunidades.

Observamos na nossa pesquisa que a utilização das espécies vegetais conecta saberes tradicionais e colabora de forma potente para a manutenção e cuidados dos ecossistemas pois a vida nos Terreiros de Candomblé e Umbanda sertanejos é a própria expressão da natureza. Todos os Orixás são e estão ligados diretamente aos elementos naturais e se expressam através deles. Essa reverencia à natureza e às divindades que ali habitam, demonstra que o homem é apenas parte de conjunto natural e harmônico maior e que urge sensibilidades para lidar com profundo respeito e cuidado na proteção deste imenso patrimônio material e imaterial.

Frente ao contexto apresentado nas Cartografias Sociais dos Terreiros de Candomblé e Umbanda no Sertão, para nós é evidente a importância de mais estudos acerca dos conhecimentos etnobotânicos, etnofarmacológicos e espirituais dos Babalorixás e Yalorixás, pois, através da utilização das plantas nas obrigações religiosas e nas cerimônias de cura se mantém o equilíbrio da vida.

\section{REFERÊNCIAS}

ADMIRADORES DA UMBANDA. O portal do Conhecimento. Disponível em: $<$ http://admiradoresdaumbanda.com.br/produto/abacateiro/ > Acesso em; 3 de abr. de 2021 
ALVES, Rômulo R.N.; DIAS, Thelma L.P. Usos de invertebrados na medicina popular no Brasil e suas implicações para conservação. Tropical Conservation Science, v.3, n.2, p.159-174. 2010.

ANDRADE, Rodrigo de Oliveira, Deficiência hídrica e clima Semiárido exigiram respostas adaptativas sofisticadas de espécies da caatinga, Especial biota educação v, As muitas faces do sertão, Edição 209, Julho 2013.

ARAÚJO, A.M., Folclore Nacional, vol.III (Ritos, sabença, linguagem, artes e técnicas), São Paulo; Melhoramentos: 1964.

Arboriza Teutonia. Disponível em: < https://www.teutonia.rs.gov.br/arborizateutonia/especies/pau-ferro/> Acesso em 24 de abr. de 2021

ASSUNÇÃO, Luis Carvalho de. Reino dos Mestres a tradição da Jurema na Umbanda Nordestina. Rio de Janeiro: Pallas, 2010.

BAPTISTEL, A.C.; COUTINHO, J.M.C.P.; LINS, E.M.F.N.; MONTEIRO, J.M. Plantas medicinais utilizadas na Comunidade Santo Antônio, Currais, Sul do Piauí: um enfoque etnobotânico. Revista Brasileira de Plantas Medicinais, Bom Jesus-PI, v. 16, n.2, p.406-425, 2014.

BARROS , J.F.P. O segredo das folhas: sistema de classificação de vegetais no Candomblé Jêje-Nagô do Brasil. Rio de Janeiro: Pallas: 1983. 147 p.

BARROS, Jose Flávio P. de; NAPOLEÃO, Eduardo, Ewé .editora: bertrand brasil $5^{\underline{a}}$ edição - 2011.

BOTELHO, Denise. Educação e Orixá: processos educativos no lle Axé lya Mi Agba. Tese (Doutorado em Educação) São Paulo: Faculdade de Educação da Universidade de São Paulo - FEUSP, 2005.

CAMARGO , M.T.L. 1988. Plantas medicinais e de rituais afro-brasileiros. São Paulo: ALMED. 97 p. In: GRUPIONI, Luís Donizete (Orgs) Índios no Brasil. Brasília: MEC, 1994. 
CERRATINGA. Disponível em:<http://www.cerratinga.org.br/licuri/> Acesso em: 23 de abr. 2021.

CULTIVAR WEB - RNC Registro Nacional de Cultivares - Disponível em: $<$ http://sistemas.agricultura.gov.br/snpc/cultivarweb/cultivares_registradas.php> Acesso em: 22 de abr. de 2021

EDUCA YORUBÁ. Disponível em: <http://educayoruba.com/10-exemplos-de-orukode-filhos-de-esu>Acesso em: 24 de abr. 2021

FUNDAÇÃO JOAQUIM NABUCO. Conselho Nacional da Reserva da Biosfera da Caatinga. Caatinga: um dos biomas mais desprotegidos do Brasil. Disponível em: $<$ Fundaj.gov.br/index.php/conselho-nacional-da-reserva-da-biosfera-dacaatinga/9762-caatinga-um-dos-biomas-menos-protegidos-dobrasil\#: :text=A\%20Caatinga\%20está\%20situada\%20> Acesso em 23 de abr. 2021

HAMPATÉ BÂ, Amadou. A Tradição viva. In: História geral da África I. ZERBO, J.K (org.).Brasília:MEC/Unesco, 1982.

HUFFMAN, Michael A. Current evidence for self-medication in primates: a multidisciplinary perspective. American Journal of Physical Anthropology, v.104, n.25, p.171-200. 1997.

HUTCHINGS, Michael R. et al. Can animals use foraging behaviour to combat parasites? Proceedings of the Nutrition Society, v.62, n.2, p.361-370.2003.

LIMA, H.C.; Lewis, G.P. \& Bueno, E. 2002. Pau-brasil: uma biografia. Pp. 39-76. In: E. Bueno (ed.). Pau-brasil. São Paulo, Axis Mundi Editora.

MARQUES, Juracy (Org.). Candomblé e Umbanda no Sertão: cartografia social dos terreiros de Paulo Afonso: Paulo Afonso-BA: Gráfica Fonte Viva; 2009.

(Org.). Candomblé e Umbanda no Sertão: Cartografia social dos Terreiros de Jaguarari: Paulo Afonso-BA: Gráfica Fonte Viva; 2010. 
MARQUES, Juracy; NOVAES, Joaquim. (Org.). Candomblé e Umbanda no Sertão: cartografia social dos terreiros de Petrolina-PE e Juazeiro-BA.Paulo Afonso; SABEH: 2015.

MARQUES, Robson (Org.) SILVA, Gilmara C.; MARQUES, Juracy. Candomblé e Umbanda no Sertão: Cartografia Social dos terreiros de Senhor do Bonfim/BA; Editora da SABEH: 2018.

MOURA, Flávia de B.P.; MARQUES, José G.W. Zooterapia popular na Chapada Diamantina: uma medicina incidental? Ciência e Saúde Coletiva, v.13, n.2, p.21792188. 2008.

NODARI, R.O.; GUERRA, M.P. 1999. Biodiversidade: aspectos biológicos, geográficos, legais e éticos. Pp. 11-24. In: C.M.O. Simões et al. (eds.). Farmacognosia da planta ao medicamento. Porto Alegre, Editoras UFRGS/ UFSC.

OXÓSSI, Diego de: A magia das Folhas:365 plantas e seus poderes. $2^{\underline{a}}$ ed. São Paulo: Arole Cultural: 2020.

PIRES, M.V. et al. Etnobotânica de terreiros de candomblé nos municípios de Ilhéus e Itabuna, Bahia, Brasil. R. bras. Bioci, Porto Alegre, v. 7, n. 1, p. 3-8, jan./mar. 2009.

SCHLEIER, Rodolfo; QUIRINO, Cristiane Sacuragui; RAHME Samir. Erythrina mulungu - descrição botânica e indicações clínicas a partir da antroposofia Erythrina Arte Médica Ampliada Vol. 36 | N. 4 | Outubro / Novembro / Dezembro de 2016

ULHÔA, Clarissa Adjuto. Essa terra aqui é de Oxum, Xangô e Oxóssi: um estudo sobre o candomblé na cidade de Goiânia. Dissertação de Mestrado. Programa de Pósgraduação em História, Universidade Federal de Goiás: 2011.

VARELLA, J.S.C. Ervas Sagradas na Umbanda. Rio de Janeiro; Ed. Espiritualista: 1973 
VERGER, P.F. Ewé: o uso das plantas na sociedade lorubá. São Paulo; Companhia das Letras: 1995

\section{APÊNDICE - REFERÊNCIA DE NOTA DE RODAPÉ}

3. Fonte: https://admiradoresdaumbanda.com.br/produto/abacateiro/ Acesso em: 13/05/2021.

4. Orúkọ -nome em Yorùbá - é a expressão que traz muita força, uma verdadeira história de vida de quem o recebe e traz com orgulho. No Candomblé os nomes não são considerados apenas nomes. Alguns iniciados temo significado do seu nome revelado somente após completar 7 anos, uma obrigação de maioridade dentro dessa tradição.

Fonte:

https://www.bibliotecaagptea.org.br/agricultura/biologia/livros/PLANTAS\%20MEDICI NAIS\%20-\%20MARIA\%20ZELIA\%20DE\%20ALMEIDA. Acesso em 13/05/2021

Enviado: Maio, 2021

Aprovado: Junho, 2021. 